\title{
BMJ Open Why did COVID-19 not further harm the mental health of poor mothers? A mixed-method study on low-income families in Singapore
}

\author{
Esther Chor Leng Goh (10), Daniel John Rongwei Wen, Rachel Chai Yun Ang
}

To cite: Goh ECL, Wen DJR, Ang RCY. Why did COVID-19 not further harm the mental health of poor mothers? A mixedmethod study on low-income families in Singapore. BMJ Open 2022;12:e052103. doi:10.1136/ bmjopen-2021-052103

- Prepublication history for this paper is available online. To view these files, please visit the journal online (http://dx.doi. org/10.1136/bmjopen-2021052103).

Received 06 April 2021 Accepted 05 January 2022

D) Check for updates

(c) Author(s) (or their employer(s)) 2022. Re-use permitted under CC BY-NC. No commercial re-use. See rights and permissions. Published by BMJ.

Department of Social Work, National University of Singapore - Kent Ridge Campus, Singapore

Correspondence to Dr Esther Chor Leng Goh; swkegcl@nus.edu.sg

\section{ABSTRACT}

Objectives This paper examines the impact of COVID-19 pandemic on a disadvantaged group of financially poor mothers' mental health conditions in Singapore during the phase of acute COVID-19 infection.

Design A mixed-method design is used. We conducted five focus group discussions with interviewers $(n=39)$ who administered a third wave of survey questionnaire to 424 mothers from low-income families between June and September 2020. The focus group discussions gleaned observations by the interviewers on the risk and stress levels of the mothers during the period leading up to the height of COVID-19 pandemic. In addition, survey data from two time points-pre-COVID-19 and post-COVID-19 pandemic height, measuring the relationship of mother's job loss, income earner loss, marital status, number of children and, permanency of employment and mother's hope levels with mother's depression and anxiety were used to triangulate the observations from the focus group discussions.

Results Majority of the interviewers did not observe any marked increase in stress levels. Correspondingly the quantitative data did not show any significant increase in depression and anxiety scores between wave 2 and 3 results. Qualitative data showed that numerous mothers were able to report different strategies in coping with the financial distress. The government COVID-19 support grants were cited by many as helpful in cushioning the financial stress. Comparing the quantitative measurements, the relationship between loss of income earner and mother's depression and anxiety was moderated by marital status. In addition, the relationship between mother's job loss and mother's depression, as well as loss of income earner and mother's anxiety, was moderated by mother's hope.

Conclusion We speculate the relatively stable level of mental health state of financially poor mothers amidst the COVID-19 pandemic to their internal (psychological traits) resilience which is facilitated by the availability of resources in the social milieu through the COVID-19 support grants.

\section{INTRODUCTION}

Researchers have hypothesised the severe negative impact of COVID-19 on the mental health, namely depression and anxiety, in

\section{Strengths and limitations of this study}

- The strength of the study is that it is one of the first that empirically tracked the mental health conditions of low-income mothers at the initial phase of COVID-19 pandemic and immediately after the peak of infection in Singapore.

- The two-time point of data revealed the extent of the impact of the pandemic on low-resource mothers mental health in the face of job and income losses.

- This paper provides rich insights into the coping strategies of the poor and government grant provisions that might have mitigated the unprecedented impact of COVID-19 on their mental health. While the mental health measurements were administered directly to the low-income mothers, in-depth qualitative insights were, however, collected from the interviewers who followed the participants over the two-time points of survey.

- Even though time, limitation of resources and social distancing prevented the collection of qualitative data directly from the relatively large sample of low-income mothers, the indirect qualitative insights corroborated with the objective mental health measurements had shed light on why COVID-19 did not further harm the mental health of the poor in Singapore.

Asian $^{12}$ and Western ${ }^{34}$ societies, particularly the socially disadvantaged groups. ${ }^{5}$ A European study on the ramifications of economic standstill, leading to consequential income loss, has revealed dire consequences on workers' mental health. ${ }^{6}$ Another UK-based study found that population prevalence of clinically significant levels of mental distress rose $8.4 \%$ from $2018 .{ }^{7}$ Yet, there is a remarkable dearth of empirical evidence on those who have been financially disadvantaged prior to the pandemic. Little is known about how the long-term poor of societies cope financially and psychologically during the sudden intensification of economic hardship. 
Among the financially disadvantaged populations, women are more vulnerable to a public health emergency $^{8}$ during a pandemic. Online cross-sectional survey collected from working women showed those with children suffered more severe mental health symptoms during COVID-19 lockdown, as compared with their counterparts without children. ${ }^{3}$ Lockdown intensified the parent-child dyadic stress not only because they were confined to the same space over extended periods of time, but also exacerbated by school closures as mothers were also left to handle their children's home-based learning (HBL). This could further contribute to parental stress which in turn negatively impact children's well-being. ${ }^{4}$ These published papers on mother and children's wellbeing during COVID-19 pandemic are instructive to this study, although they did not target low-income samples. We aim to extend literature by focusing on low-income mothers who are in long-term financial stress. Beyond cross-sectional data, we used two short-term longitudinal data sets to examine the impact of the pandemic on the low-income mothers' mental health conditions and coping strategies.

\section{The chronicles of COVID-19 pandemic in Singapore}

In response to the fast-evolving crisis, a multiministry task force was formed to pre-empt the potential risks and mitigate the ramifications of COVID-19 in Singapore. ${ }^{9}$ To stem the spread of the virus, a nationwide partial lockdown, known as circuit-breaker, was implemented between 7 April 2020 and 4 May $2020{ }^{10}$ and this was subsequently extended to 1 June $2020{ }^{11}$ Only essential services and key economic sectors could keep their premises open whereas non-essential industries were ordered to close. ${ }^{12}$ On 1 June 2020, circuit-breaker measures were progressively lifted in three phases: phase 1 (Safe Re-opening), phase 2 (Safe Transition) and phase 3 (Safe Nation).

The tightened safety measures have extensive social, psychological and economic consequences on all strata of the Singapore population. On the psychological front, panic buying, social isolation, poor mental health, and domestic violence had been reported. ${ }^{13-15}$ Economically, it was estimated that the lockdown safety measures had reduced Singapore's annual real gross domestic product by $2.2 \%$, chalking up a total economic cost of about $\$ \$ 11$ billion. ${ }^{16}$ The abrupt pull-back in economic activity and adjustments made by businesses to cope meant that many who were not employed in essential services or who could not work remotely, had to face reduced working hours, no-pay leave and income losses. ${ }^{17} 18$ To cushion the economic impact, the Singapore government introduced four budgets (ie, unity, resilience, solidarity and fortitude budgets) from February to May 2020, with subsequent enhancements. The resilience and solidarity budgets focus on helping companies and saving jobs and providing social support to households. The fortitude budget provides critical support for affected employees and firms, particularly in job search in growth areas. ${ }^{16} 19$

For employees, measures included the Jobs Support Scheme (JSS), which provided up to $75 \%$ support on the first $\mathrm{S} \$ 4600$ (approximately US $\$ 3480$ ) of monthly wages for 10 months; and up to $50 \%$ of the same in the subsequent 7 months period. ${ }^{20}$ For job seekers, the SGUnited Jobs and Skills package provided 100000 jobs, job placement support, traineeship, and upgrading opportunities. ${ }^{21}$ For self-employed persons (SEPs) with limited family support, the SEP Income Relief Scheme provided $\$ \$ 1000$ (approximately US\$758) cash payout per month for 9 months and a training support scheme to help SEPs be future-ready through skills upgrading and training. ${ }^{162}$ For households, each adult Singaporean received a Solidarity Payment cash payout of $\$ \$ 600$ (approximately US\$455) and Care and Support cash of up to $\mathbf{S} \$ 900$ (approximately US\$669) for those with low income. For adult Singaporean parents with at least one Singaporean child, they received an additional S\$300 (approximately US\$223) each. ${ }^{23}$ The COVID-19 support grant and the Temporary Relief Fund targeted the low-income to middle-income individuals. Specifically, the COVID-19 support grant, provided employees (ie, prior monthly per capita income $\leq \$ \$ 3100$ or approximately US\$2297) with job loss or income loss with up to $\mathbf{S} \$ 800$ (approximately US\$595) per month for 3 months whereas the Temporary Relief Fund provided employees (ie, prior monthly per capita income $\leq \$ \$ 3100$ or approximately US $\$ 2297$ ) with job loss or income loss with a one-off $\mathbf{S} \$ 500$ (approximately US\$379) cash payout. ${ }^{24}$

\section{Present study}

In the current paper, we investigated the impact of COVID-19 on the levels of depression and anxiety of mothers from low-income families. Due to the unprecedented nature of the pandemic, we sought to first explore how COVID-19 impacted mothers based on qualitative methods. The themes generated from the qualitative methods were then triangulated with statistical analysis of the survey measurements administered at two time points- that is, pre and post height of COVID-19 infection-to a sample of low-income mothers.

In tandem with examining the negative impact of the unforeseen stresses and challenges brought about by the pandemic, this paper also pays close attention to the possible resilience and strengths that might mitigate the risks on this disadvantaged population. Beyond the resilience and hope found at the individual level during COVID-19 pandemic documented in existing literature,${ }^{25}$ we explored resilience in the microfamilial ${ }^{26}$ and socialecological ${ }^{27}$ milieus and the interactions of the multidimensions of resilience. Proponents of social ecological resilience posit that the opportunity structures that surround an individual will shape the individual's capacity to experience resilience when facing adversity. ${ }^{28}$

\section{METHODS}

To address the research questions set out in this paper, a mixed method approach was used. The quantitative data stemmed from a larger study ${ }^{29}$ where three waves of short-term longitudinal surveys were administered across 
three time points to low-income mothers and children, with 6 months intervals, between 2019 and 2020. For this paper, only survey measurements on the mental health and resilience reported by low-income mothers were included, analysed and compared with examine the differences in outcomes.

Qualitative data, on the other hand, were collected from five focused group discussions (FGDs) with interviewers $(n=39)$ who followed the same participants across the three time points of surveys. These interviewers who had established rapport with the participants in earlier waves of surveys, were tasked to conduct a brief open-ended risk assessments on all the mothers before implementing the survey in wave 3. By juxtaposing the results of qualitative data from FGDs which captured the observations of lowincome mothers surveyed by the interviewers; and the self-reported results on mothers' mental health and resilience survey measurements collected in two time points, this paper provides insights on the effect of COVID-19 on the mental health of these low-income mothers.

\section{Qualitative focus group discussions \\ Brief Risk Assessment}

The research team amended the original protocol of the original study ${ }^{29}$ introduced a basic semblance of psychological first aid (PFA). The moral obligation in studying a vulnerable population in the period which coincided with the unforeseen pandemic compelled the research team to implement a brief risk assessment to understand the stress and risk levels of all mothers as part of wave 3 . The goal was to refer those in need to relevant services. The brief open-ended risk assessment adapted the action principles of 'look-listen-link' of PFA WHO. ${ }^{30}$

The 42 interviewers were appropriate candidates for conducting the risk assessment for three reasons. First, the majority were trained social workers or current social work students, or adults with experience in early childhood education or in human services. It is reasonable to assume that they have a considerable level of ability to attend to human emotions. Second, all interviewers were required to attend a 3-hour webinar training on attending to signs of risk during assessment. Third, some level of familiarity and trust had been established between the participants and interviewers.

The three open-ended questions for the brief risk assessment were: (1) 'How has the circuit-breaker been for you'? As there has been a rise in cases involving domestic violence in Singapore during circuit-breaker, ${ }^{31}$ this question allowed the participants to express any stress they may experience; (2) 'How did you and your children manage HBL'? This question stemmed from a published local paper on school closure intensifying parental stress which resulted in increased harsh parenting ${ }^{32}$; (3a) 'How has COVID-19 affected your job, health and emotions'? The interrelatedness of job stability and financial stress on physical and emotional health has been established in literature ${ }^{33}$; (3b) 'Is there any support you need'? This question served the purpose of linking the mothers to the required social services. The interviewers were also tasked to take note if the participants had any observable injuries, and to pay attention if participants disclosed depressive symptoms and financial difficulties. Formal referrals to social service agencies were made on behalf of the participants to obtain required services and support.

\section{FGD with Interviewers}

To collect the observations by the interviewers on the brief risk assessment implemented, five FGD via zoom were conducted by the principal investigator and a fulltime research assistant (RA) after the completion of wave 3 survey. Thirty-nine out of 42 interviewers took part in the FGDs. Each focused group lasted for an average duration of $100 \mathrm{~min}$. In total, $500 \mathrm{~min}$ of recordings were transcribed verbatim for analysis.

\section{Data analysis}

The first author, an experienced qualitative researcher, together with an RA (here after as the 'analyst team') combed through the transcripts and inductively developed the skeleton coding structure. With the aim of being immersed in the data, the RA read the transcripts extensively and coded with the aid of the Nvivo V.12 software. After an initial line-by-line coding of all transcripts by the RA, the analyst team reviewed all the codes regularly and discussed any inconsistencies in interpretation to refine the coding structure. Through an iterative process, the analyst team integrated the sixty-five open codes into 10 axial codes, which included 'impact of COVID-19 on jobs', 'emotional stress' and 'management of financial stress'. These were further categorised under two salient themes: 'risk' and 'hope'. These two themes were used to guide the examination of the survey measurements.

\section{Quantitative survey \\ Sample}

Mother-child dyads were recruited for the larger study on low-income families in Singapore. ${ }^{29}$ These families were receiving government financial aid at the time of recruitment or had previously received financial aid at one point during the 3 years before the time of recruitment. They also had a child between 7 and 12 years. Government financial aid provided temporary financial support to low-income individuals or families who were temporarily unable to work, were looking for a job or were earning a low income and required assistance. Wave $2 \quad(n=480$ dyads) and wave 3 ( $n=462$ dyads) of the study were conducted from December 2019 to February 2020, and June 2020 to October 2020, respectively. For the purpose of this paper, only the mothers' data were examined. The mothers were from the four main ethnic groups in Singapore-Chinese $(n=76)$, Malay $(n=290)$, Indian $(n=69)$ and Others $(n=27)$. Each dyad who participated in the study received a token of $\mathbf{S} \$ 80$ (approximately US\$60) at wave US\$60) at wave 2 and $\mathbf{S} \$ 110$ (approximately US\$80) at wave 3 . 


\section{Measurements}

\section{Depression Anxiety and Stress Scale}

The Depression Anxiety and Stress Scale (DASS-21) ${ }^{34}$ was administered to mothers to assess their mental health at wave 2 and wave 3 . The DASS-21 measures emotional distress in three subcategories-depression, anxiety and stress. It consists of 21 items with 7 in each category. Participants were asked to rate which statements applied to them over the past week, with 0 (did not apply to me at all) to 3 (applied to me most of the time.) The higher the score, the more severe the emotional distress was. To calculate comparable scores with full DASS, each sevenitem scale was multiplied by two. Cronbach's alpha for the depression and anxiety subscales was 0.879 and 0.822 , respectively, at wave 3 in this sample.

\section{Parenting Sense of Competence Scale}

The Parenting Sense of Competence (PSOC) Scale was administered to mothers at wave 2 and wave 3 to assess their satisfaction in parenting and their self-efficacy in the parenting role. ${ }^{35}$ The PSOC Scale contains 17 items that were rated on a 6-point scale: 1 (strongly disagree) and 6 (strongly agree). The higher the total score, the greater the mother's sense of competence in parenting. Cronbach's alpha for the total scale was 0.768 and 0.817 at wave 2 and wave 3 , respectively.

\section{Child Behaviour Checklist 6-18}

The Child Behaviour Checklist 6-18 (CBCL 6-18) was administered to mothers at wave 2 and wave 3 to assess the emotional and behavioural problems of their children. ${ }^{36}$ The CBCL contains 113 items that were rated on a 3-point scale: 0 (not true), 1 (somewhat or sometimes true) and 2 (very true or often true). The Total Problems score indicates the overall degree of emotional and behavioural problems, based on responses to all CBCL items. The higher the score, the more emotional and behavioural problems were assessed to be reported. Cronbach's alpha for the total problems scale was 0.952 and 0.949 at wave 2 and wave 3 respectively.

\section{Trait Hope scale}

The Trait Hope Scale (THS) ${ }^{37}$ was administered at wave 3 to assess mother's dispositional hope through eight items measuring agency and pathway. Agency refers to the sense of successful determination in meeting goals. Pathway refers to the sense of being able to generate successful plans to meet goals. All items used an 8-point response scale, from 1 (definitely false) to 8 (definitely true); with greater THS scores reflecting higher levels of trait hope. In this study, Cronbach's alpha for the overall scale, agency subscale and pathways subscale were 0.800 , 0.558 and 0.579 , respectively, at wave 3 .

\section{Sociodemographic data}

Additional data were obtained from demographic questionnaires. This included mother's job status at wave 2 and wave 3 , number of income earners in the family at wave 2 and wave 3 , marital status at wave 3 , number of children at wave 3, permanency of employment at wave 3. To quantify the mother's job loss, mothers who held a job at wave 2 but not at wave 3 were coded as 1 and all other mothers were coded as 0 . To quantify the loss of income earner, a code of 1 was given to mothers when the number of income earners decreased from wave 2 to wave 3 and a code of 0 was given to all other mothers.

\section{Data analysis}

To further triangulate both the quantitative and qualitative data, independent sample t-tests were used to analyse the group differences in mother's job loss, permanency of mother's job, loss of income earner on mother's depression and anxiety. Paired samples t-test were used to analyse differences in mother's PSOC, child's total behaviour problems, mother's depression and mother's anxiety across wave 2 and wave 3 . Factorial analyses of variance were used to analyse interaction effects of mother's job loss $\times$ marital status, mother's job loss $\times$ number of children, loss of income earner $\times$ marital status, and loss of income earner $\times$ number of children on mother's depression and anxiety.

Multiple linear regression was used to analyse the separate interaction effects of mother's job loss $\times$ number of children, loss of income earner $\times$ number of children, mother's job loss $\times$ mother's hope and loss of income earner $\times$ mother's hope on mother's depression and anxiety. The main effects and interaction effect were entered into the regression model. Where significant interaction effects were found, simple slopes analysis was conducted as a post hoc test in line with the suggestions of Aiken et al. ${ }^{38}$ To investigate which component of mother's hope was responsible for the significant relations found, mother's hope was replaced by the two subscales 'mother's agency' and 'mother's pathways' in separate follow-up analyses.

\section{Patients and public involvement}

Neither patients nor the public were involved in the development of the research design, nor in the conduct, reporting or dissemination plans of this study.

\section{Findings}

The qualitative data, gathered from the interviewers' observations during FGDs, showed about one-fifth of the mothers had experienced financial stress that stemmed directly or indirectly from COVID-19. Few interviewers reported observations of emotional distress because of the pandemic during the risk assessments. Contrary to the findings in recent studies on how the pandemic has gravely affected disadvantaged population worldwide, the low-income mothers in Singapore cited a range of strategies to manage their financial and emotional stress. Using the government COVID-19 payouts was the most prominent strategy. Mothers were observed to maintain a reasonable level of hope despite jobs and income losses. 


\section{Financial stress}

One-fifth of the mothers were observed to experience financial stress. Single mothers who were the sole income earners or whose sole breadwinner-husbands had lost their jobs, reported being financially affected and needed some help to tide them through: 'she had to go on [coping with the finances]. She was already receiving assistance but was still not enough, so I referred her to the family service centre for food assistance' (I-14). It was an unexpected finding that about four-fifth of the mothers did not show extreme financial stress.

The mothers had shared how COVID-19 hit their family finances but were not disproportionately distressed: 'there is a trend that many found the stress is heavier. But I did not see any exhibiting great distress' (I-30). 'Majority of the mothers reported that they have enough food but just a bit tight on budget. They cope by cutting down on spending.' (I-09).

Income and job losses as a result of curtailment of economic activities because lockdown did not indiscriminately impact them. Those who held lowly paid jobs kept their jobs as these were classified as essential services. Also, some mothers reported that they kept their jobs because of the government's JSS. Other mothers who were in the gig economy were more adversely affected: 'almost $50 \%$ of the mothers' jobs were affected including those who had to work from home (WFH). Generally, everyone took a more positive attitude, no one really told me that she needs urgent help.' (I-12).

Comparing across time points, the interviewers reported observing higher level of financial stress in wave 3 but not insurmountable: 'I just feel like in general, the families in wave 3 felt heavier financial stress. But not so severe that the mothers cannot function' (I-30). The mothers were able to cope with the financial stress in wave 3 . For the one-fifth of mothers who experienced financial stress, they commonly reported seeking help from family service centres.

\section{Emotional stress}

The emotional stress observed by the interviewers, though reported with lower frequencies as compared with financial stress, could broadly be grouped under those that were related to the pandemic. A source of emotional stress that two interviewers observed, stemming from financial stress, was observed among households with only one income. The income reduction or loss of job means that they have to work longer hours or cope with the loss of the only income: 'I think she was a bit emotional when talking about her husband. Because her husband was the sole breadwinner. And all the kids at home. I think it's just a lot of pressure for them.' (I-21).

A related emotional stressor is school closure during circuit-breaker. Children had stayed/remained home for online classes, or HBL. Mothers felt stressed having to WFH and attend to their children at the same time. They needed to juggle their work while ensuring that their children were engaged in online classes. They shared
Table 1 Descriptive statistics of study variables

\begin{tabular}{|c|c|}
\hline Variable & $\begin{array}{l}\text { Wave } 3 \\
\text { sample } \\
(\mathrm{N}=462)\end{array}$ \\
\hline Mother's depression score, mean (SD) & $6.75(8.02)$ \\
\hline Mother's anxiety score, mean (SD) & $7.52(8.10)$ \\
\hline Mother's hope score, mean (SD) & $48.59(7.67)$ \\
\hline Mother's agency score, mean (SD) & $23.24(4.60)$ \\
\hline Mother's pathways score, mean (SD) & $25.35(4.01)$ \\
\hline No of children, mean (SD) & $3.50(1.67)$ \\
\hline $\begin{array}{l}\text { Mother's parenting sense of competence } \\
\text { score, mean (SD) }\end{array}$ & $69.36(10.66)$ \\
\hline $\begin{array}{l}\text { Child's total behaviour problems score, } \\
\text { mean (SD) }\end{array}$ & $23.64(19.32)$ \\
\hline \multicolumn{2}{|l|}{ Mother's job loss, \% } \\
\hline Did not lose job & 89.2 \\
\hline Lost job & 10.8 \\
\hline \multicolumn{2}{|l|}{ Loss of income earner, \% } \\
\hline Did not lose income earner & 84.2 \\
\hline Loss of income earner(s) & 15.8 \\
\hline \multicolumn{2}{|l|}{ Mother's permanency of employment, \% } \\
\hline Full time employment & 43.7 \\
\hline Part time or contract employment & 56.3 \\
\hline \multicolumn{2}{|l|}{ Mother's marital status, \% } \\
\hline Unmarried & 31.8 \\
\hline Married & 68.2 \\
\hline
\end{tabular}

feeling inadequate to be their children's tutors. Eight interviewers reported that mothers felt stressed as they only had one laptop to share in the family, although some mothers managed to loan laptops from schools. Some children had to take turns to sit out of classes. HBL was particularly stressful for the mothers if one or more of their children have special needs.

Social distancing and safety measures during lockdown also meant that these mothers were deprived of social support. One interviewer reported that:

'For one particular mother, her stress was more apparent, and she was more emotional (as compared with previous two time points). There was no support especially during the circuit-breaker, there wasn't anyone to talk to. She has a young kid, a primary school going kid. she feels very alone and the [tight] finances were not helping her a lot as well.' (I-13)

\section{Quantitative results: effect of Job/income loss on depression and anxiety}

The list of descriptive statistics of the variables used in this study can be found in table 1 . Statistical analysis revealed that mothers who lost their own job between wave 2 and 3 did not have significantly different levels of depression $(\mathrm{t}(460)=-0.309, \mathrm{p}=0.758$; table 2 .) or anxiety $(\mathrm{t}(460)=$ 
Table 2 The effect of job/income loss on mother's depression and anxiety

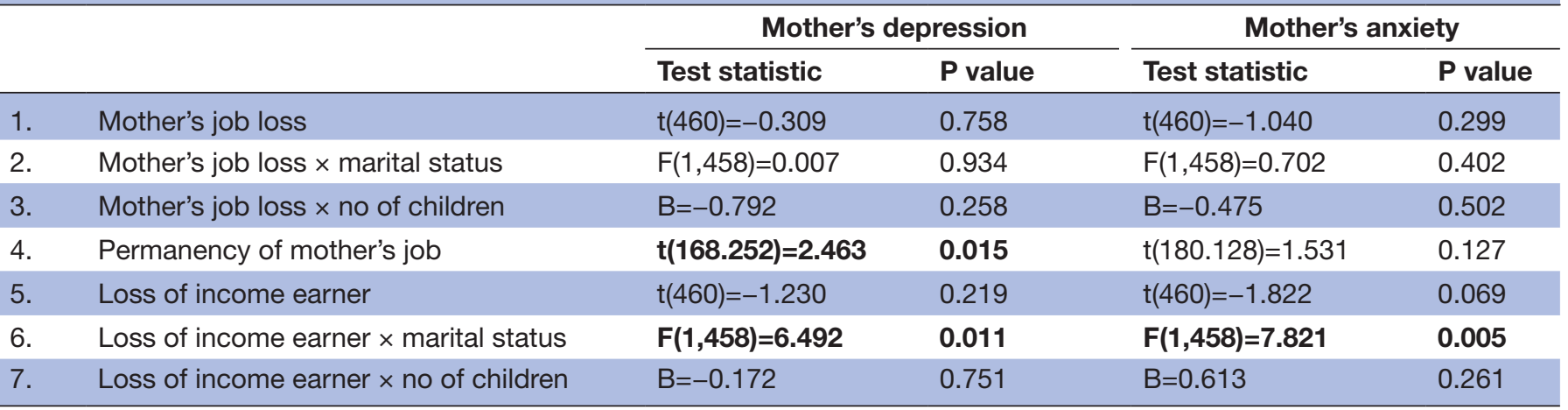

Significant results are bolded.

$-1.040, \mathrm{p}=0.299)$ at wave 3 when compared with mothers who did not lose their own job between wave 2 and 3$)$. The effect of mothers' own job loss on depression $(\mathrm{F}(1,458)=$ $0.007, \mathrm{p}=0.934)$ and anxiety $(\mathrm{F}(1,458)=0.702, \mathrm{p}=0.402)$ was not moderated by their marital status at wave 3 . The effect of mother's job loss between wave 2 and 3 on depression $(\mathrm{B}=-0.792, \mathrm{p}=0.258)$ and anxiety $(\mathrm{B}=-0.475$, $\mathrm{p}=0.502$ ) was also not moderated by the number of children at wave 3 . However, the permanency of the mother's job at wave 3 had a significant effect on mother's depression $(\mathrm{t}(168.252)=2.463, \mathrm{p}=0.015$; table 2$)$. Mothers who worked full time at wave $3(\mathrm{M}=5.248, \mathrm{SD}=5.906)$ had lower depression scores than mothers who were not working full time (ie, part time or contract work; $\mathrm{M}=7.670, \mathrm{SD}=8.168$ ). The permanency of the mother's job at wave 3 did not have a significant effect on the mother's anxiety levels at wave $3(\mathrm{t}(180.128)=1.531, \mathrm{p}=0.127)$.

Furthermore, statistical analysis revealed that there were no differences in wave 3 depression $(\mathrm{t}(460)=-1.230$, $\mathrm{p}=0.219$; table 2$)$ or anxiety levels $(\mathrm{t}(460)=-1.822$, $p=0.069)$ of mothers who experienced the loss of income earners from wave 2 to wave 3 compared with those who did not. The effect of loss of income earner on wave 3 depression $(\mathrm{F}(1,458)=6.492, \mathrm{p}=0.011$; figure $1 \mathrm{~A})$ and anxiety levels $(\mathrm{F}(1,458)=7.821, \mathrm{p}=0.005$; figure $1 \mathrm{~B})$ of mothers was moderated by marital status at wave 3 . Unmarried mothers showed significant higher levels of depression $(\mathrm{p}=0.006)$ when they experienced a loss in income earners $(\mathrm{M}=10.692$, $\mathrm{SD}=11.757)$ as compared with those who $\operatorname{did} \operatorname{not}(\mathrm{M}=5.884$, $\mathrm{SD}=7.318)$. This difference in depression levels of mothers were not found when the mother was married $(p=0.613)$. Similarly, unmarried mothers showed significantly higher levels of wave 3 anxiety $(\mathrm{p}=0.001)$ when they experienced a loss in income earners $(\mathrm{M}=12.308, \mathrm{SD}=10.624)$ as compared with mothers who did not $(\mathrm{M}=6.512, \mathrm{SD}=7.111)$. This significant difference in anxiety levels were not found in mothers who were married $(\mathrm{p}=0.864)$. Furthermore, the number of children in the family at wave 3 did not moderate the effect of job loss on their depression $(\mathrm{B}=-0.172, \mathrm{p}=0.751)$ or anxiety levels $(\mathrm{B}=0.613, \mathrm{p}=0.261)$.

Lastly, to investigate if the changes introduced during COVID-19, such as HBL and WFH were related to increased parenting stress, we investigated the changes in PSOC and child's total behaviour problems across wave 2 and wave 3. A paired samples t-test indicated that there were no significant differences in mother's PSOC ( $t(461)$ $=1.956, \mathrm{p}=0.051$ ) across wave 2 and wave 3 . Furthermore, a paired samples t-test indicated that there were no significant differences in child's total behaviour problems $(\mathrm{t}(461)=-0.509, \mathrm{p}=0.611)$ across wave 2 and wave 3 .

B

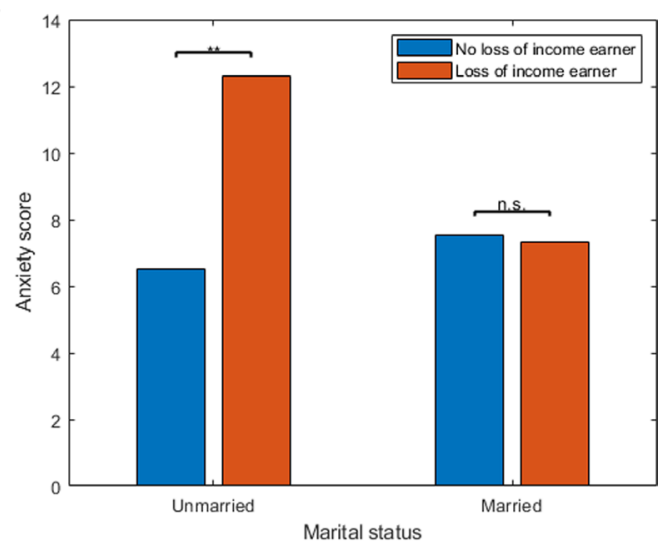

Figure 1 Bar charts of interaction of marital status and loss of income earner on (A) mother's depression and (B) mother's anxiety. ${ }^{*} \mathrm{P}<0.01,{ }^{* *} \mathrm{p}<0.001$. Blue bar represents mothers who did not lose income earner(s); orange bar represents mothers who lost income earner(s). n.s, not significant. 


\section{Resilience and strategies in coping with stress}

Similar to the financial and emotional stresses observed, resilience and adaptability in coping with stress emerged clearly in the analysis. Seven interviewers highlighted that the mothers viewed COVID-19 with a positive light. The interviewers were surprised to see that the mothers maintained a cheerful and positive attitude: 'the facial expressions and the voice tone [not different from previous waves]. And how quick[ly] the replies [to the survey questionnaires] came about. For those [who took the pandemic as a] positive experience during the pandemic, the answers came forth quite fast.' (I-26). This observation was echoed by other interviewers who detected positive and cheerful tone of voice during wave 3 survey: 'They are pretty cheerful, spontaneous and from their answers [to the survey questionnaire] they are aligned with what they said. That means that they are alright.' (I-31). One mother was reported to be 'super happy' that COVID-19 happened: 'she said the entire family was at home I am so happy, we eat together, I can spend time with them' (I-28). In addition to the unexpected positive outlook, qualitative data analysis revealed salient adaptive strategies used by the mothers to cope with stress.

\section{Utilized government COVID-19 payouts}

The most frequently mentioned support by the mothers were the government COVID-19 payouts ( $n=13)$. Participants who experienced job loss cited how the payouts were helpful to tide them over the period:

'I have one... mother where the husband lost his job. The family felt that financially okay. They mentioned that the government have handouts. So, for that month they were able to survive. They felt like they did not need [further] financial assistance even though there were no income earners in the family.' (I-06)

'There were a few families who were struggling a bit financially but not at the stage of crisis. A few of them asked if they could be referred [for further help] even though they were recipients of financial assistance from Social Service Office. Several of them said they were grateful with the COVID-19 grants. Without it, it would be real struggle for them.' (I-34)

Although there was a range of government schemes, participants were able to identify the appropriate scheme that matched their eligibility. For instance, a mother who resigned before the pandemic and became a freelance full-time delivery rider, shared that she planned to apply under the scheme targeted at SEPs.

\section{Found another job}

The second common strategy $(n=12)$ to cope was to proactively look for another job. The participants did not express great difficulty in looking for jobs. Some mothers, who reported job loss, went through a short period of financial stress, although not prolonged: 'they said their husband managed to grab some other jobs during that period' (I-28). Upgrading their skills was another way that mothers proactively increased their employability: 'they try to find a new job or upgrade their skills' (I-07). Interviewers also reported that the mothers actively sought help from social service agencies when looking for jobs. They seemed to be well versed with the available community resources and had established links with these sources of help: 'they said they had already approached the Family Service Centres or Social Service Office and did not need extra help information. The mothers expressed appreciation to the social workers who managed to assist them in job hunting' (I-29). While many reported that they were already connected with social service agencies in the community, 32 referrals were made by the interviewers as a result of the risk assessment conducted. These mothers expressed the need for additional help. The implicit meaning of such adaptive behaviours revealed that lowincome families were not plagued by an overwhelming sense of helplessness or hopelessness when facing the unforeseen pandemic.

\section{Started home-based business}

Several interviewers reported that participants had started home-based catering or baking business:

'But then actually two mothers told me that they were starting home-based business. So, one of them said it [circuit-breaker] was good [be]cause kids can help her with like the baking and everything. So, it was kinda good that they were home.' (I-10)

There were no data on whether these businesses survived or thrived. This, however, reflects the resilience of these low-income families in responding to the crisis. Based on observations over three time points, interviewers attributed their adaptability to the low-income families' familiarity with coping with crisis: 'they are used to living from hand to mouth.' (I-35). Hence, their frame of mind was to 'carry on and this is what we got to do' mindset (I-15). The participants seem to take the unforeseen stress of COVID-19 in their stride.

\section{Quantitative results: hope as moderator}

We investigated if the mother's mental health was severely impacted by the onset of COVID-19. Paired samples t-tests indicated that there were no significant differences in depression $(\mathrm{t}(461)=-0.904, \mathrm{p}=0.367)$ and anxiety $(\mathrm{t}(461)$ $=-0.321, \mathrm{p}=0.749)$ from wave 2 to wave 3 . In addition, we investigated if the effect of mother's own job loss on depression and anxiety would be moderated by mother's hope. Mother's hope at wave 3 moderated the effect of job loss from wave 2 to wave 3 on their depression at wave 3 ( $\mathrm{B}=-0.285, \mathrm{p}=0.027$; table 3 ; figure $2 \mathrm{~A})$. When mother's hope was low, mothers who lost their job showed a trend for significantly higher depression scores than mothers who did not lose their job $(b=2.616, p=0.079)$. When mother's hope was high there were no significant differences in depression scores between mothers who lost their job and those who did not $(\mathrm{b}=-1.751, \mathrm{p}=0.235)$. On further 
Table 3 Mother's hope as a moderator for the relationship between job/income loss and mother's depression and anxiety

\begin{tabular}{|c|c|c|c|c|c|}
\hline & \multicolumn{2}{|c|}{ Mother's depression } & \multicolumn{2}{|c|}{ Mother's anxiety } \\
\hline & & Test statistic & P value & Test statistic & P value \\
\hline 1. & Mother's job loss $\times$ mother's hope & $B=-0.285$ & 0.027 & $b=-0.204$ & 0.138 \\
\hline 3. & Mother's job loss $\times$ mother's agency & $B=-0.333$ & 0.123 & - & - \\
\hline 4. & Loss of income earner $\times$ mother's hope & $B=-0.229$ & 0.062 & $B=-0.313$ & 0.016 \\
\hline 6. & Loss of income earner $\times$ mother's agency & - & - & $B=-0.411$ & 0.055 \\
\hline
\end{tabular}

Significant results are bolded.

investigation, this moderation effect was explained by the pathway subscale $(b=-0.878, p=0.001$; figure 2B) and not the agency subscale $(b=-0.333, p=0.123)$. When mother's pathways scores were low, mother's job loss was associated with a significantly higher depression scores $(b=4.247, p=0.008)$ than those who did not experience job loss. When mother's pathways scores were high, mother's job loss was associated with a trend for significantly lower depression than those who did not lose their job $(\mathrm{B}=-2.785, \mathrm{p}=0.069)$. Hope was not found to moderate the effect of mother's job loss on the mother's anxiety $(\mathrm{b}=-0.204, \mathrm{p}=0.138)$.

We also sought to investigate if the effect of the loss of an income earner in the family on depression and anxiety would be moderated by mother's hope. The effect of loss of income earners from wave 2 to wave 3 on mother's depression scores at wave 3 was not significantly moderated by mother's hope $(\mathrm{B}=-0.229, \mathrm{p}=0.062$; table 3$)$. The effect of loss of income earners from wave 2 to wave 3 on mother's anxiety scores at wave 3 was significantly
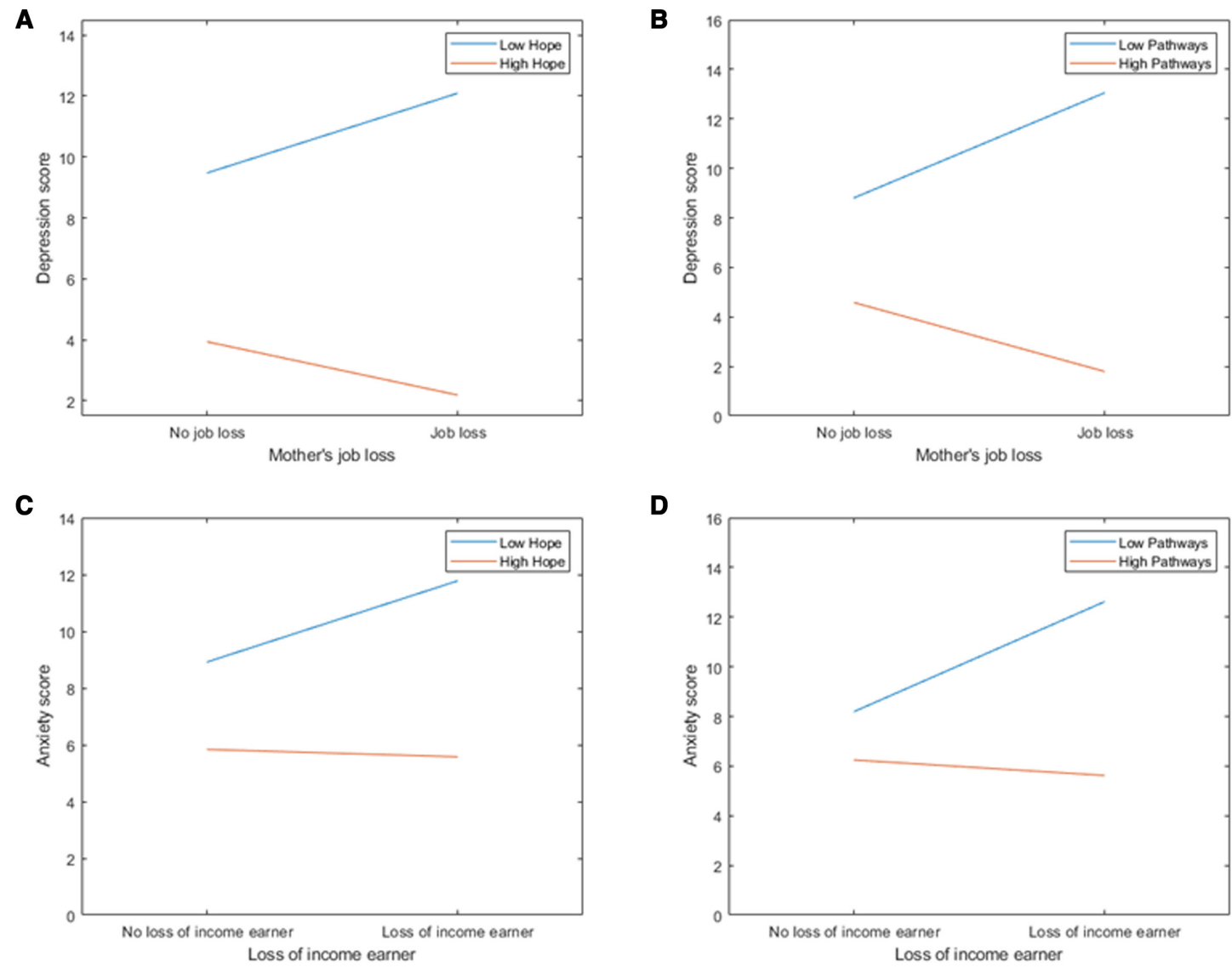

Figure 2 Plots of (A) interaction of mother's job loss and mother's hope on mother's depression; (B) interaction of mother's job loss and mother's pathways on mother's depression; $(\mathrm{C})$ interaction of loss of income earner and mother's hope on mother's anxiety and (D) interaction of loss of income earner and mother's pathways on mother's anxiety. Blue line represents mothers with low hope; orange line represents mothers with high hope. 
moderated by mother's hope at wave $3 \quad(B=-0.313$, $\mathrm{p}=0.016$ ), figure $2 \mathrm{C}$ ). When mother's hope was low, loss of income earners was associated with a significant increase in anxiety $(\mathrm{B}=4.014, \mathrm{p}=0.004)$. When mother's hope was high, the loss of income earners did not associate with a change in anxiety $(\mathrm{B}=-0.791 \mathrm{p}=0.586)$. This moderation was further explained by the pathways subscale $(\mathrm{B}=-0.630, \mathrm{p}=0.015$; figure $2 \mathrm{D})$ and not the agency subscale $(\mathrm{B}=-0.411, \mathrm{p}=0.055)$. When mother's pathways score was low, loss of income earners was associated with a significant increase in anxiety $(\mathrm{B}=4.429, \mathrm{p}=0.002)$. This was not observed when the mother's pathways score was high $(\mathrm{B}=-0.622, \mathrm{p}=0.667)$.

\section{DISCUSSION}

Corroborating the qualitative findings based on interviewers' observations of participants and statistical results based on the participants' survey responses, showed probable explications to the relatively stable mental health state of low-income families in Singapore despite the impact of COVID-19. The risk assessments conducted by interviewers on low-income mothers did not reveal extensive dire stress as predicted in literature. Heavier stress was reported by most mothers but only a few considered themselves in despair. Descriptive statistic, in wave 3 survey, showed a low proportion of mothers who lost their own jobs $(10.8 \%)$ or income earners in their families (15.8\%). Statistical analysis among mothers who had jobs, revealed that the permanency of jobs seems to be a protective factor against depression. Even for lowskilled and low-paid jobs classified as essential services, including cleaners and grocery workers, contributed to a sense of security of income. With regard to the loss of income earners in these women's households during the pandemic, being married seems to be a protection against anxiety. Having a spouse to weather the financial stress together could have mitigated the sense of threat and anticipated risk as compared with unmarried women. Two aspects of emotional stress revealed in the open-ended qualitative data were the stress of having to manage HBL of multiple children at home because of school closure, and the prohibition of accessing natural support network because of social distancing. Although captured in the qualitative data based on interviewers' observations, significant differences in terms of PSOC and child total behaviour problems were not found in the quantitative analysis of the survey responses. The differences in the qualitative and quantitative data could indicate that while these challenges exist in the midst of the pandemic, they were not pronounced enough to be detected statistically. Notwithstanding the financial and emotional stress reported, a sense of hope and resilience prevailed amidst the pandemic. This is an unexpected and yet prominent finding.

\section{Hope and resilience amidst pandemic}

Hope is a psychological resource that motivates and drives future action and positive outcomes. We rely on hope to yield positive outcomes in difficult circumstances. ${ }^{39}$ Resilience, on the other hand, involves the capacity to adapt despite adversity. That is resilient families are those who successfully engaged with risk rather than evaded risk. ${ }^{40}$ Individuals and families that are measured high in hope factors tend to engage longer and more persistently in a risk context to solve the problem and manage the impact of that risk. Both hope and resilience could potentially explain the ways in which poor families fare relatively well despite adversity. ${ }^{39}$

Triangulating the qualitative observations and statistical analysis revealed that hope and resilience were demonstrated quite evidently among the low-income population amidst the pandemic. There was no statistically significant difference in the mothers' mental health states between waves 2 and 3 of survey. These results did not conform with the hypothesised negative impact of COVID-19 on the mental health of socially disadvantaged groups. ${ }^{15}$ Among the $10 \%$ and $15 \%$ of mothers who lost jobs or income earners, their levels of hope significantly moderated the impact on their level of depression and anxiety. Instead of a pervasive sense of helplessness, convergence of the pathway subscale scores and qualitative observations by interviewers, these women clearly demonstrated their will power. ${ }^{41}$ That is, they possessed the perceived capability of imagining one or more routes to their goals.

Government COVID-19 payouts were cited by mothers as an important resource that tided them over the income reduction months and prevented them from plunging into a state of crisis. Not only did the low-income mothers use government payouts, but they were also knowledgeable in applying through the assistance of social workers, other applicable COVID-19 grants. Well informed of community resources including Family Service Centres and Social Service Offices and willingness to step forward to seek help revealed their proactive adaptive behaviours. Such active proactive coping could partly be attributed to the fact that these mothers, being in low-income brackets, are familiar with managing crisis. And the viable option for them is to choose 'this is what we have to do' survival mentality instead of resignation and passivity.

Low-income families also exhibited resilience in searching for jobs. Women reported that the job losses did not last for a long time as they were able to find another job, participated in skills upgrading training or started small home-based businesses. Essential full-time jobs like cleaners and grocery workers, though lowly pay, were protective factors that prevented them from depression. The caveat for such internal resilience must be understood within the external context of the society. We posit that the external resilience of Singapore's economic and COVID-19 policy contexts enabled such internal resilience. Recent socioecological resilience literature expanded the lens of resilience beyond internal dimension where strengths are found to locate within individual and family strengths to include external dimension. Internal resilience is believed to be influenced by the broader external context, which in turn, influences the 
family's internal context and the meaning they give to a particular stressful event. Proponents of ecological resilience $^{27}$ posits that resilience is a consequence of congruence between individual needs and the environment that facilitate growth.

\section{Policy context that facilitated internal resilience}

Around the world, policy-makers have taken actions to mitigate the economic repercussions of the coronavirusinduced global recession. ${ }^{4243}$ These actions, which include targeted fiscal measures and monetary measures, were advocated by the international monetary ${ }^{44}$ as necessary to support affected household and businesses domestically, and to maintain economic relationships internationally so that economic activities can gradually normalise once the pandemic abates and containment measures are lifted. ${ }^{44}$ Against this backdrop, there are several attributes in the political and economic context of Singapore, that may have facilitated the internal resilience of the study respondents. First, Singapore has a strong fiscal capacity with a total national reserve that is estimated to be well above SS $\$ 500$ billion (approximately US $\$ 370$ billion), and this reserve has been drawn on during times of crisis. ${ }^{45}$

To cushion the impact of COVID-19, four budgets had been rolled out by the government and this comprised an expected overlay of $\mathbf{\$} \$ 100$ billion (approximately US $\$ 74$ billion), with $\mathbf{\$} \$ 52$ billion (approximately US\$38 billion) to be drawn from past reserves. ${ }^{46}$ This translated to practical and timely financial help for its residents as cash transfer were vital for the poor who can spend them on necessities whereas unemployment benefits supported consumption for those who experienced job loss. This shows that many of the schemes were targeted at the most vulnerable in Singapore, as they receive greater, although still time-limited support to tide the crisis. ${ }^{47}$ Second, Singapore has taken an entire government approach to managing COVID-19 and when coupled with her high political centralisation, this meant that the government is able to pass legislation quickly such as the drawing of past reserves. ${ }^{48}$ Also, the economic schemes are well timed to coincide with the established domestic laws so that when the public health measures and human control measures kick in to restrict human and therefore economic activities, the shock on lives and livelihoods are cushioned. Third, the vulnerable and lowincome groups in Singapore have access to information on the government support schemes and payouts, as details about the schemes were actively circulated and easily accessible through local news media (eg, television, radio, print). The communication was also done in a clear, consistent, and timely manner. Fourth, the administration of the schemes also facilitated the access to help by those from the lower socio-economic group. For example, the one-off $\mathbf{S} \$ 600$ Solidarity Payment was an automatically disbursed cash payout, given to all adult Singaporeans without the need for application. The qualitative empirical evidence of this paper, though collected through observations of survey interviews and not directly from the participants, revealed that poor mothers did not have difficulty tapping into these funds. The potential barriers to access that comes with an application process such as stigma or physical barriers ${ }^{49}$ were minimised.

\section{CONCLUSION AND POLICY IMPLICATIONS}

This paper highlights that despite the uncertainties of the COVID-19 pandemic, the mental health of financially poor mothers is relatively stable. As a result of the significant resources provided by the Singapore government, the financially poor mothers have gathered various adaptive strategies to cope with the unexpected financial distress. This external (social milieu) resilience bolstered the financially poor mothers' internal (psychological traits) resilience. Specifically, the availability of COVID-19 payout grants facilitated the coping processes and resilience in the familial and individual levels of low-income families, thus enhancing their stress-adaption processes. ${ }^{50}$ Therefore, the study found that the injection of fiscal policies by the Singapore government was effectively geared to save the livelihoods of the people. However, as Singapore begins transition from a pandemic to an endemic, ${ }^{51}$ a vital question to ask is: what does this mean for the livelihood and mental health of these poor mothers? This is a potential area for future research.

Moving forward, Singapore's policy-makers will have to continue to carefully weigh the benefits, costs, and risks of these fiscal measures. On a social front, fiscal measures may need to continue or even be scaled up to protect the livelihood of its people. This is especially crucial if the stoppages to economic activity are persistent or if the pickup in economic activity is still weak despite the lifting of social restrictions. ${ }^{44}$ It is also noteworthy that on an economic front, many policies that provided essential support in the short-term may have longer-term implications. ${ }^{52}$ It is on this challenging terrain that Singapore's policy-makers need to navigate their policy response.

Contributors ECLG led the writing of the manuscript. DJRW conducted the statistical analysis and writing of the results of these measurements. RCYA was responsible for the chronicles of the COVID-19 pandemic in Singapore as well as subsidies by the government. All the authors revised and approved the final version of the manuscript. ECLG acts as a gaurantor of this study.

Funding This research project is funded by the Singapore Ministry of Education Social Science Research Thematic Grant M0E2016-SSRTG-039 granted to the first author.

Disclaimer We are grateful to the Ministry of Social and Family Development (MSF) in facilitating the collection of data for this paper. MSF does not endorse the research project or its findings, methods or results in any way, and any views, findings or results arising from the research project in the publication or presentation are strictly the authors' own.

Competing interests None declared.

Patient and public involvement Patients and/or the public were not involved in the design, or conduct, or reporting, or dissemination plans of this research.

Patient consent for publication Not applicable.

Ethics approval This study was approved by NUS-IRB reference code: S-18-003 DERC Reference Code: ER370-250920.

Provenance and peer review Not commissioned; externally peer reviewed. 
Data availability statement Data of this paper are not available due to the nondisclosure agreement signed to protect confidentiality of participants.

Open access This is an open access article distributed in accordance with the Creative Commons Attribution Non Commercial (CC BY-NC 4.0) license, which permits others to distribute, remix, adapt, build upon this work non-commercially, and license their derivative works on different terms, provided the original work is properly cited, appropriate credit is given, any changes made indicated, and the use is non-commercial. See: http://creativecommons.org/licenses/by-nc/4.0/.

\section{ORCID iD}

Esther Chor Leng Goh http://orcid.org/0000-0002-0235-2363

\section{REFERENCES}

1 Poudel K, Subedi P. Impact of COVID-19 pandemic on socioeconomic and mental health aspects in Nepal. Int J Soc Psychiatry 2020;66:748-55.

2 Mamun MA, Ullah I. COVID-19 suicides in Pakistan, dying off not COVID-19 fear but poverty? - The forthcoming economic challenges for a developing country. Brain Behav Immun 2020;87:163-6.

3 Benassi E, Vallone M, Camia M. Women during the Covid-19 lockdown: more anxiety symptoms in women with children than without children and role of the resilience. Mediterr J Clin Psychol 2020;8:1-19 https://cab.unime.it/journals/index.php/MJCP/article/ view/2559/0

4 Spinelli M, Lionetti F, Pastore M, et al. Parents' stress and children's psychological problems in families facing the COVID-19 outbreak in Italy. Front Psychol 2020;11:1713.

5 Purtle J. COVID-19 and mental health equity in the United States. Soc Psychiatry Psychiatr Epidemiol 2020;55:969-71.

6 Witteveen D, Velthorst E. Economic hardship and mental health complaints during COVID-19. Proc Natl Acad Sci U S A 2020;117:27277-84

7 Pierce $\mathrm{M}$, Hope $\mathrm{H}$, Ford $\mathrm{T}$, et al. Mental health before and during the COVID-19 pandemic: a longitudinal probability sample survey of the UK population. Lancet Psychiatry 2020;7:883-92.

8 Azcona G, Bhatt A, Encarnacion J. From insights to action: gender equality in the wake of COVID-19. United nations entity for gender equality and the Empowerment of women (un women), 2020. Available: https://www.unwomen.org/en/digital-library/publications/ 2020/09/gender-equality-in-the-wake-of-covid-19 [Accessed 01 Sept 2021].

9 Abu Baker J. Singapore forms Wuhan virus ministerial task force, imported case 'inevitable': Gan Kim Yong, 2020. Channel news Asia. Available: https://www.channelnewsasia.com/news/singapore/ wuhan-virus-singapore-ministerial-task-force-inevitable-12301610 [Accessed 24 Mar 2021].

10 Yong M. Timeline: how the COVID-19 outbreak has evolved in Singapore so far, 2020. Channel news Asia. Available: https:// www.channelnewsasia.com/news/singapore/singapore-covid-19outbreak-evolved-coronavirus-deaths-timeline-12639444 [Accessed 24 Mar 2021].

11 Govsg. Circuit breaker extension and tighter measures: what you need to know, 2020. Available: https://www.gov.sg/article/circuitbreaker-extension-and-tighter-measures-what-you-need-to-know [Accessed 24 Mar 2021].

12 In full: PM Lee's address on enhanced measures to deal with COVID-19 situation in Singapore, 2020. Channel news Asia. Available: https://www.channelnewsasia.com/news/singapore/ coronavirus-covid-19-lee-hsien-loong-update-address-nation-tv12606328 [Accessed 24 Mar 2021].

13 Chong C. Panic buying, circuit breaker and reopening: A timeline of S'pore's Covid-19 fight, 2020. The Straits times. Available: https:// www.straitstimes.com/singapore/panic-buying-circuit-breaker-andreopening-a-timeline-of-spores-covid-19-fight [Accessed 24 Mar 2021].

14 Han G. Seniors felt less socially satisfied, more isolated during Covid-19 circuit breaker period: survey, 2020. The Straits times. Available: https://www.straitstimes.com/singapore/lowersatisfaction-levels-higher-social-isolation-for-senior-citizensduring-circuit\#: :text=SINGAPORE\%20-\%20Social\%20isolation\% 20during\%20the \%20circuit\%20breaker,in\%20May\%20when\% [Accessed 24 Mar 2021].

15 Tai J. Coronavirus: elderly hit hard by social isolation amid circuit breaker measures, 2020. The Straits times. Available: https://www. straitstimes.com/singapore/health/elderly-hit-hard-by-socialisolation-amid-circuit-breaker-measures [Accessed 24 Mar 2021].
16 Saw C, Koh W, Foo X. Economic survey of Singapore second quarter 2020, 2020. Available: https://www.mti.gov.sg/-/media/MTI/ Resources/Economic-Survey-of-Singapore/2020/Economic-Surveyof-Singapore-Second-Quarter-2020/FA_2Q20.pdf [Accessed 24 Mar 2021]

17 Tangs S. MAS expects more job losses, wage cuts as economy deals with 'large, abrupt shock' from COVID-19, 2020. Channel news Asia. Available: https://www.channelnewsasia.com/news/singapore/ covid-19-mas-more-job-losses-wage-cuts-large-abrupt-shock12683068 [Accessed 24 Mar 2021].

18 Singapore airlines to cut 4,300 jobs due to pandemic, most in its history, 2020. The economic times. Available: https://economictimes. indiatimes.com/news/international/business/singapore-airlines-tocut-4300-jobs-due-to-coronavirus-pandemic/articleshow/78037729. cms [Accessed 24 Mar 2021].

19 Min $\mathrm{CH}$. Parliament passes Fortitude budget, 4th package of COVID-19 relief measures this year, 2020. Channel news Asia. Available: https://www.channelnewsasia.com/news/singapore/ fortitude-budget-covid-19-parliament-passes-heng-swee-keat12808172 [Accessed 24 Mar 2021].

20 Inland Revenue Authority of Singapore. Jobs support scheme (JSS), 2020. Available: https://www.iras.gov.sg/irashome/Schemes/ Businesses/Jobs-Support-Scheme-JSS-/ [Accessed 24 Mar 2021].

21 Ministry of Manpower. Support for local jobseekers through SGUnited jobs and skills package, 2020. Available: https://www. mom.gov.sg/newsroom/press-releases/2020/0526-sgunited-jobsand-skills-package [Accessed 24 Mar 2021].

22 Ministry of Manpower. About 88,000 to automatically benefit from self-employed person income relief scheme, 2020. Available: https:// www.mom.gov.sg/newsroom/press-releases/2020/0327-about88000-to-automatically-benefit-from-self-employed-person-incomerelief-scheme [Accessed 24 Mar 2021].

23 Ministry of Finance. Budget, 2020. Available: https://www. singaporebudget.gov.sg/budget_2020/budget-measures/care-andsupport-package [Accessed 24 Mar 2021].

24 Yuen S. All adult Singaporeans to receive one-off $\$ 600$ Solidarity Payment in April to cope with Covid-19, 2020. The Straits times. Available: https://www.straitstimes.com/politics/all-adultsingaporeans-to-receive-one-off-600-solidarity-payment-in-april [Accessed 24 Mar 2021]

25 Yıldırım M, Arslan G. Exploring the associations between resilience, dispositional hope, preventive behaviours, subjective well-being, and psychological health among adults during early stage of COVID-19. Curr Psychol 2020:1-11.

26 Panter-Brick C, Eggerman M. Understanding culture, resilience, and mental health: The production of hope. In: The social ecology of resilience. London: Springer, 2012: 369-86.

27 Ungar M. Social ecologies and their contribution to resilience. In: The social ecology of resilience. London: Springer, 2012: 13-32.

28 Laub JH, Sampson RJ. Shared beginnings, divergent lives: delinquent boys to age 70. Cambridge, MA: Harvard University Press, 2003.

29 Goh ECL, Chong WH, Mohanty J, et al. Identifying positive adaptive pathways in low-income families in Singapore: protocol for sequential, longitudinal mixed-methods design. JMIR Res Protoc 2019;8:e11629.

30 World Health Organization. World Health organization, 2020. Available: http://www.who.int/ [Accessed 24 Mar 2021].

31 lau J. Coronavirus: more cases of family violence during circuit breaker; police to proactively help victims, 2020. Available: https:// str.sg/JApp [Accessed 24 Mar 2021].

32 Chung G, Lanier P, Wong PYJ. Mediating effects of parental stress on harsh parenting and parent-child relationship during coronavirus (COVID-19) pandemic in Singapore. J Fam Violence 2020:1-12.

33 Thoits PA. Stress and health: major findings and policy implications. $J$ Health Soc Behav 2010;51 Suppl:S41-53.

34 Lovibond PF, Lovibond SH. The structure of negative emotional states: comparison of the depression anxiety stress scales (DASS) with the Beck depression and anxiety inventories. Behav Res Ther 1995;33:335-43.

35 Johnston C, Mash EJ. A measure of parenting satisfaction and efficacy. J Clin Child Psychol 1989;18:167-75.

36 Achenbach TM, Rescorla L. Manual for the ASEBA SchoolAge Forms \& Profiles: An Integrated System of Multi-informant Assessment. Burlington, VT: ASEBA, 2001.

37 Snyder CR, Harris C, Anderson JR, et al. The will and the ways: development and validation of an individual-differences measure of hope. J Pers Soc Psychol 1991;60:570-85.

38 Aiken LS, West SG, Reno RR. Multiple regression: testing and interpreting interactions. Newbury Park, Calif: Sage Publications, 1991. 
39 Maholmes V. Fostering resilience and well-being in children and families in poverty: why hope still matters. New York, NY: Oxford University Press, 2014.

40 Kalil A. Family resilience and good child outcomes. A review of the literature. Wellington, New Zealand: Centre for Social Research and Evaluation, Ministry of Social Development, 2003.

41 Snyder CR. The psychology of hope: you can get there from here. London, England: Simon and Schuster, 1994.

42 Benmelech E, Tzur-llan N. The determinants of fiscal and monetary policies during the COVID-19 crisis. SSRN Journal 2020;25.

43 Ozili PK, Arun T. Spillover of COVID-19: impact on the global economy. SSRN Journal 2020;10.

44 International Monetary Fund. World economic outlook, 2020. Available: https://www.imf.org/en/Publications/WEO/Issues/2020/04/ 14/weo-april-2020 [Accessed 24 Mar 2021].

45 JY N. Singapore's giant reserves: a taxing question for its next prime minister, Heng Swee Keat, 2019. South China morning post. Available: https://www.scmp.com/week-asia/politics/article/ 2186409/singapores-giant-reserves-taxing-question-its-next-primeminister [Accessed 25 Mar 2021].

$46 \mathrm{Lim}$ YL. 33b set aside in Fortitude Budget, bringing Singapore's Covid-19 war chest to nearly 100 billion, 2020. The Straits times. Available: https://www.straitstimes.com/politics/parliament-33- billion-set-aside-in-fortitude-budget-bringing-covid-19-war-chest-tonearly [Accessed 24 Mar 2021]

47 Quah D. Singapore's policy response to Covid-19. In: Baldwin R, Weder MB, eds. Mitigating the Covid economic crisis: act fast and do whatever it takes. London: CEPR, 2020: 103.

48 Abdullah AZ. President Halimah Yacob gives 'in-principle support' to draw on reserves for second COVID-19 assistance package. CNA 2020. Available: https://www.channelnewsasia.com/news/singapore/ president-halimah-yacob-gives-in-principle-support-reserves12578562 [Accessed 24 Mar 2021].

49 Socialprotection.org. Barriers to access social assistance and special social services in Kazakhstan. Available: https://socialprotection.org/ discover/publications/barriers-access-social-assistance-and-specialsocial-services-kazakhstan [Accessed 24 Mar 2021]

50 Lu L, Chen CS. Correlates of coping behaviours: internal and external resources. Couns Psychol Q 1996;9:297-307.

51 Khalik S. Moving from Covid-19 pandemic to endemic: Singapore's strategy and how it can unfold, 2021. The Straits times. Available: https://www.straitstimes.com/singapore/health/moving-from-covid19-pandemic-to-endemic [Accessed 01 Sep 2021].

52 International Monetary Fund. Fiscal monitor: policies for the recovery. Available: https://www.imf.org/en/Publications/FM/Issues/2020/09/ 30/october-2020-fiscal-monitor [Accessed 01 Sep 2021]. 